\title{
Note on Some Observations About the Post-lepromin Scar
}

\author{
J. WALTER, ${ }^{*}$ C. T. TAMONDONG $\dagger$ P. GALLEGO GARBAJOSA, \\ L. M. BECHELLI, $\S$ H. SANSARRICQ,\| KYAW LWIN, $₫$ AND \\ MAUNG MAUNG GYI**
}

\begin{abstract}
The post-lepromin scar was studied in 764 leprosy patients of the former (1964-1975) WHO Leprosy BCG Trial in Burma, Mandalay area. A

bac./ml lepromin was used. Scar formation was analysed in its relation to the different forms of leprosy, its frequency to the size of the Mitsuda reaction, to BCG vaccination, to the tuberculin reaction, and, in some instances, in different age groups. $90.2 \%$ of the BCG vaccinated cases (336) showed post-lepromin scars whilst in the controls (410 cases) $80 \%$ had a scar. Five hundred and fifty-three $(74 \%)$ of 746 cases had post-lepromin scars on first testing, and of the remaining 193 cases, $78(40 \%)$ developed lepromin scars on subsequent lepromin testing. One hundred and fifteen patients (15\%) remained scar negative throughout the period even after repeated lepromin testing (up to 6 tests). Ten of these constant scar-negative cases subsequently developed lepromatous and borderline forms; 38 were diagnosed as having indeterminate, 63 tuberculoid and 4 " $T r$ " leprosy.

It is tentatively suggested that the post-lepromin scar may be considered as an indicator for a stabilized immune situation, taking into account that $17-32 \%$ of the 2-5 mm late Mitsuda readings also leave post-lepromin scars.

Further studies with weaker lepromins (20 or 40 million bac./ml) in leprosy patients and in apparently non-leprosy affected groups of populations are suggested.
\end{abstract}

\section{Introduction}

Some reviews (Sato, 1967; Bechelli et al., 1971) of the lepromin test list up to 270 references. However, the post-lepromin scar is the stepchild of the Mitsuda reaction. The Transactions of the VIIth International Congress of Leprology, Tokyo (1958, pp. 464-465), briefly refer to the lepromin scar by stating: ". . . the late lepromin reaction ... later regresses, frequently leaving atrophy or a scar".

Post-lepromin scar formation in the different forms of leprosy, in different age groups, and its frequency in relation to the Mitsuda reaction, to BCG vaccination, and to the tuberculin reaction was studied in 746 leprosy patients of the former WHO Leprosy BCG Trial in the Mandalay area, Burma (1964-1975).

Received for publication 6 January, 1977.

* Medical Officer, Leprosy Unit, WHO, Geneva, Switzerland; † WHO Statistician, Burma; $\ddagger$ Former WHO Medical Officer, Burma; § Former Chief Medical Officer, retired and Prof essor of Dermatology, Faculty of Medicine, Ribeirao Prêto, Brazil; \|| Chief Medical Officer, Leprosy Unit, WHO, Geneva, Switzerland; I Deputy Director, Leprosy Control, Ministry of Health, Rangoon, Burma and ** Medical Officer, Leprosy/BCG Trial, Burma. 
The post-lepromin scar, which is hypopigmented, rarely more than $2-10 \mathrm{~mm}$ in diameter, and never of a keloid character, is best read at least 3-4 months after the late lepromin reaction and is perfectly visible after many years. The post-lepromin "scar" may follow either ulceration, or, less frequently, 3-5 mm (1+) and $6-10 \mathrm{~mm}(2+)$ reactions without necrosis or ulceration which leave, as a consequence of the inflammatory process, what French authors call "atrophie cicatricielle". For practical purposes scars and "atrophie cicatricielle" have been considered together under the title "scar".

Throughout the study a lepromin $(\mathrm{H})$ preparation of $160 \mathrm{million} \mathrm{bac} . / \mathrm{ml}$ was used. The "standard" lepromin was kindly supplied by Dr Abe of the National Institute for Leprosy Research, Tokyo. For reasons of comparability, this provisional (Tokyo, 1958) standard remained unaltered, although $\pm 10 \%$ of false reactions could not be excluded with certainty.

The frequency of scars in the trial (Bechelli et al., 1970 is related to the size of the late lepromin reaction. Nodules of $10 \mathrm{~mm}$ and above following lepromin injection, and particularly ulcers, nearly always leave a scar. Scars are less frequently associated with smaller nodules $(3-8 \mathrm{~mm})$. For operational reasons, the size of the scar in this study was not related to the late Mitsuda reading.

Of the 794 cases, in the 2 (BCG vaccinated and control) trial groups diagnosed up to June, 1973, data on the lepromin scar is available for 746. During subsequent follow-up studies (1973-1975) the number of cases increased to 996. An analysis of these data, regarding scar formation, will be the subject of a further study with one exception, namely, the diagnosis of lepromatous and borderline cases during the years 1974-1975. As will be shown later, the inability of multibacillary ( $\mathrm{L}$ and $\mathrm{B}$ ) forms of leprosy to develop a lepromin scar is considered to be a constant feature.

Of the 746 cases that have been followed up, 336 belong to the BCG group, while 410 belong to the control group.

\section{Results and Discussion}

The data given in Table 1 suggest that BCG vaccination enhanced the lepromin-scar formation and confirm previously published data and findings which showed a comparable composition of the vaccinated and control group (Bechelli et al., 1973-1974).

TABLE 1

Percentage of cases with scar on first or subsequent

lepromin tests

\begin{tabular}{lccc}
\hline & BCG group & Controls & $\begin{array}{c}\text { Difference } \\
\text { (BCG-controls) } \\
\%\end{array}$ \\
\hline 746 & 90.2 & 80.0 & $10.2^{*}$ \\
T cases & 93.6 & 86.2 & 7.4 \\
Ot hers $\dagger$ & 76.5 & 60.6 & 15.9 \\
$(\mathrm{I}, \operatorname{Tr}(\mathrm{B})$ and L) & & & \\
\hline
\end{tabular}

* The difference is statistically significant.

† Of 81 indeterminate cases, the BCG group had 11 without scar while in the controls there remained 27 who even on repeated lepromin testing never developed a scar. 
If, and this would be subject to confirmation, scar formation is an expression of a stable immune situation (corresponding to a strong lepromin reaction), a better prognosis of scar-positive cases is likely. The prognostic value of the Mitsuda reaction was extensively studied by de Souza and de Souza, who in 1948, published a 5-year follow-up observation, involving $216 \mathrm{I}$ and $685 \mathrm{~T}$ cases. According to these authors, an initial 3+ Mitsuda reaction in the vast majority of cases indicated a favourable prognosis confirming Dharmendra (1967) and Rotberg and Bechelli (1950).

With regard to scar formation and the tuberculin test, the data showed that scar formation was enhanced by BCG vaccination among those cases with tuberculin reactions of less than $10 \mathrm{~mm}$ at intake. In subjects with a PPD reaction at intake of $10 \mathrm{~mm}$ or more, BCG vaccination apparently did not have a significant influence on scar formation.

Of the 746 leprosy cases followed up, 196 did not develop a scar on first lepromin testing. In a few instances there were as many as 6 lepromin retestings but in the majority only one subsequent testing was done. In both groups, BCG and controls, about $40 \%$ of these 196 non-scar forming subjects developed scars on subsequent lepromin testing. In the tuberculoid group, $50 \%$ showed scars on retesting compared to $26 \%$ subsequent scar formation in other cases (I, Tr, B and L). In general, those with weak Mitsuda reaction (3-5 mm) at first testing showed a lower conversion rate to scar positivity on subsequent testings compared to those with stronger Mitsuda reactions ( $6 \mathrm{~mm}$ and more in the first testing).

Concerning the relationship between the size of the Mitsuda reaction and the frequency of scar formation the data are as shown in Table 2.

TABLE 2

Mitsuda reaction and scar formation; first testing in leprosy patients

\begin{tabular}{cccc}
\hline \multirow{2}{*}{$\begin{array}{c}\text { Mitsuda } \\
\text { reaction }(\mathrm{mm})\end{array}$} & $\begin{array}{c}\text { Number } \\
\text { of cases }\end{array}$ & Number & Per cent \\
\hline $\begin{array}{c}0-2 \\
(- \text { and } \pm) \\
3-5\end{array}$ & 24 & 2 & 8 \\
$(1+)$ & 184 & 49 & 27 \\
$6-9$ & 118 & 82 & 69 \\
$(2+)$ & 420 & 420 & 100 \\
$>10+(u)$ & & & \\
$(3+)$ & 746 & 553 & 74 \\
Total & & & \\
\hline
\end{tabular}

It is evident that the greater the size of the Mitsuda reaction the higher the probability of scar formation. Seventy-four per cent of cases having a 2 to $<10 \mathrm{~mm}$ late lepromin reaction developed post-lepromin scars on first testing leaving 193 scar-negative cases.

On subsequent testing, $40 \%$ of 193 cases, who did not develop a scar in the first instance, eventually had scars leaving 115 cases scar negative throughout the time of observation (see Table 6). 
TABLE 3

Mitsuda reaction and scar formation on subsequent lepromin testing in 193 non-scar forming cases on first testing

\begin{tabular}{cccc}
\hline $\begin{array}{c}\text { Mitsuda } \\
(\mathrm{mm})\end{array}$ & $\begin{array}{c}\text { Number } \\
\text { of cases }\end{array}$ & Number & Per cent \\
\hline $0-2$ & 22 & 6 & 27 \\
$3-5$ & 135 & 54 & 40 \\
$6-9$ & 36 & 18 & 50 \\
$>10+(\mathrm{u})$ & - & - & - \\
Total & 193 & 78 & 40 \\
\hline
\end{tabular}

When lepromin-scar development, after first and subsequent lepromin testing, is taken together, it appears from the data of the Burma trial that the percentage of cases developing scars in relation to the size of the lepromin reaction is as given in Table 4.

TABLE 4

First and subsequent testing

\begin{tabular}{cc}
\hline $\begin{array}{c}\text { Mitsuda } \\
\text { reaction } \\
(\mathrm{mm})\end{array}$ & $\begin{array}{c}\text { Percentage of patients } \\
\text { with scar }\end{array}$ \\
\hline $0-2$ & 17 \\
$3-5$ & 32 \\
$6-9$ & 64 \\
$>10+(\mathrm{u})$ & 100 \\
\hline
\end{tabular}

Although the $6-10 \mathrm{~mm}$ reactions including ulceration have the highest percentage of scar formation, as can be expected, a 17-32\% scar formation, following the weaker $(2-5 \mathrm{~mm})$ reactions is also of interest.

Regarding classification, the distribution of 746 cases with data on scar formation on first and repeated lepromin testing was as shown in Table 5.

TABLE 5

Clinical classification

\begin{tabular}{lrrrrrrr}
\hline & & & & & \multicolumn{2}{c}{ Total } \\
& T & I & TR & B & L & No. & $\%$ \\
\hline No. of scar-positive cases: & 524 & 96 & 11 & 0 & 0 & 631 & 85 \\
No. & 63 & 38 & 4 & 3 & 7 & 115 & 15 \\
$\quad$ Total: & 587 & 134 & 15 & 3 & 7 & 746 & - \\
\hline $\begin{array}{l}\text { Percentage of scar-positive } \\
\quad \text { cases: }\end{array}$ & 89 & 72 & 73 & 0 & 0 & \\
$\begin{array}{l}\text { Percentage of scar-negative } \\
\quad \text { cases: }\end{array}$ & 11 & 28 & 27 & 100 & 100 & \\
\hline
\end{tabular}


Of 746 repeated lepromin-tested cases not subdivided into BCG-vaccinated cases and controls. $84 \%$ were scar positive and $15 \%$ remained scar negative which included $10 \mathrm{~B}$ and L cases, $27 \%$ of $\mathrm{Tr}, 28 \%$ of I and $11 \%$ of $\mathrm{T}$ cases.

An analysis, by age and classification, of these 115 constant lepromin scar-negative cases is given in Table 6.

TABLE 6

Age and classification analysis

\begin{tabular}{lrrrrrr}
\hline Age & T & I & Tr & B & L & Total \\
\hline $0-4$ & 3 & 0 & 0 & 0 & 0 & 3 \\
$5-9$ & 20 & 16 & 0 & 1 & 1 & 38 \\
$10-14$ & 27 & 18 & 2 & 0 & 6 & 53 \\
$15-19$ & 12 & 4 & 2 & 2 & 0 & 20 \\
20 and over & 1 & 0 & 0 & 0 & 0 & 1 \\
Total & 63 & 38 & 4 & 3 & 7 & 115 \\
Bact. & 1 & 1 & 4 & 3 & 7 & 16 \\
positive & & & & & & \\
\hline
\end{tabular}

When $10 \mathrm{~B}$ and $\mathrm{L}$ cases are deducted from the above, there still remain 105 cases, including $63 \mathrm{~T}$ cases, which remained scar negative. Ninety-four of these 105 cases had Mitsuda reactions between 4-9 $\mathrm{mm}$. The number of Mitsuda doubtful cases in this group was 11. Information on the evolution of these 105 cases will only become available after further periods of observation, which are in progress.

An examination of lepromin-scar formation in household contacts of leprosy patients showed that the proportion with scars in non-household contacts was greater than among household contacts; however, the difference was not significant. No scar formation was observed in 10 histologically confirmed L, LL, BL and BB trial cases, as shown, in Table 7.

TABLE 7

\begin{tabular}{|c|c|c|c|c|c|c|c|}
\hline \multirow{2}{*}{$\begin{array}{l}\text { Code } \\
\text { 8-05 }\end{array}$} & \multicolumn{3}{|c|}{$\begin{array}{l}\text { 1st clinical diagnosis } \\
+ \text { lepromin }\end{array}$} & \multicolumn{3}{|c|}{ Evolution } & \multirow{2}{*}{$\begin{array}{c}\begin{array}{c}\text { Histological } \\
\text { diagnosis }\end{array} \\
\text { BB } 1973\end{array}$} \\
\hline & 1969 & 1 & $3 \mathrm{~mm}$ & 1973 & $\mathrm{~L}$ & $1 \mathrm{~mm}$ & \\
\hline $16-04$ & 1971 & "Tr"* & $2 \mathrm{~mm}$ & 1973 & $\mathrm{~L}$ & $1 \mathrm{~mm}$ & BL 1974 \\
\hline $83-07$ & 1969 & "Tr" & $0 \mathrm{~mm}$ & 1973 & $\mathrm{~L}$ & $2 \mathrm{~mm}$ & Early L 1973 \\
\hline $41-05$ & 1974 & B & $0 \mathrm{~mm}$ & 1975 & $\mathrm{~B}$ & $2 \mathrm{~mm}$ & BL 1974 \\
\hline $64-03$ & 1967 & "Tr" & $6 \mathrm{~mm}$ & 1975 & $\mathrm{~L}$ & $1 \mathrm{~mm}$ & Pre-L 1973 \\
\hline $76-09$ & 1968 & "Tr" & $3 \mathrm{~mm}$ & 1976 & $\mathrm{~B}$ & $4 \mathrm{~mm}$ & Resid. B 1974 \\
\hline $12-03$ & 1969 & "Tr" & $2 \mathrm{~mm}$ & 1974 & $\mathrm{~L}$ & neg. & Pre-L 1973 \\
\hline $139-05$ & 1969 & "Tr" & $5 \mathrm{~mm}$ & 1973 & $\mathrm{~L}$ & $1 \mathrm{~mm}$ & L 1973 \\
\hline $140-03$ & 1969 & "Tr" & $0 \mathrm{~mm}$ & 1973 & $\mathrm{~L}$ & $0 \mathrm{~mm}$ & BL 1974 \\
\hline $155-03$ & 1969 & B & $3 \mathrm{~mm}$ & & - & & BB 1976 \\
\hline
\end{tabular}

* The use of tuberculoid in reaction (Tr) stems from the protocol of the trial (1964) and a certain number of $\operatorname{Tr}$ cases have evolved to B forms or perhaps some of them could have been nistologically classified as B cases when they were detected. 
Five of these $10 \mathrm{~L}$ and $\mathrm{B}$ cases had late lepromin reactions at first diagnosis between 3 and $6 \mathrm{~mm}$; however, all 10 were scar negative from the time of first clinical signs and remained so throughout the period of observation.

A small group of 15 adults were tested in 1974 in a double-blind study using a weaker lepromin (40 million bac./ml). Results are shown in Table 8.

TABLE 8

\begin{tabular}{lcccc}
\hline & \multicolumn{2}{c}{ First testing } & \multicolumn{2}{c}{ Second testing } \\
Mitsuda & $\begin{array}{c}\text { Scar } \\
\text { average } \\
(\mathrm{mm})\end{array}$ & $\begin{array}{c}\text { Mitsuda } \\
\text { average } \\
(\mathrm{mm})\end{array}$ & $\begin{array}{c}\text { Scar } \\
\text { average } \\
(\mathrm{mm})\end{array}$ & $\begin{array}{c}\text { average } \\
(\mathrm{mm})\end{array}$ \\
\hline 5 Cases TT & 8.6 & 4.0 & 9.0 & 4.0 \\
5 Cases LL & 0. & 0. & 0.0 & 0. \\
5 Unaffected & 6.0 & 3.4 & 7.4 & 4.0 \\
\hline
\end{tabular}

As far as it is permissible to draw any conclusions from such a small group, there was good correlation between the lepromin test on first and second testing, sharing a constant average of scar sizes for TT cases and a slight increase in clinically non-leprosy affected subjects. LL cases all had, as expected, a negative Mitsuda and no scar formation.

\section{Conclusions}

From the above study it is tentatively concluded that:

(a) the post-lepromin scar, subject to further studies, might be regarded as a reliable indicator of a stabilized immune situation and could be a means of identifying high resistant individuals in the population; and

(b) its absence may help to recognize the false or doubtful lepromin-positive reactions in lepromatous and perhaps also in indeterminate cases, replacing, particularly under field conditions, histopathological examination of the lepromin nodule.

On the basis of the reported data, the interpretation of a certain proportion of lepromin reactions in the range between $3-5 \mathrm{~mm}$ may be raised. An exchange of experience and a repetition of the Burma study on the lepromin scar, even with smaller groups of patients but with the inclusion of clinically unaffected persons, using weaker antigen (20 or 40 million bac. $/ \mathrm{ml}$ ) could help in clarifying the significance of the post-lepromin scar.

\section{References}

Bechelli, L. M. et al. (1971). Acta leprol., Genève 42-43, 4.

Bechelli, L. M. et al. (1970). Bull. Wld Hlth Org. 42, 235.

Bechelli, L. M. et al. (1973). Bull. Wld Hlth Org. 48, 113.

Bechelli, L. M. et al. (1974). Bull. Wld Hlth Org. 51, 93.

de Souza Lima, L. and de Souza Campos, N. (1948). Int. J. Leprosy 16, 9.

Dharmendra (1967). Notes on leprosy, 2 nd edit., pp. 140, 379. New Delhi: The Ministry of Health, Government of India.

Rotberg, A. and Bechelli, L. M. (1950). Tratado de leprologia, 2nd edit. Vol. 7, p. 403. Rio de Janeira: Serviço Nacional de Lepra.

Sato, S. (1967). Human and murine leprosy. In Mykobakterien und Mykobakterielle Krankheiten, Vol. 4, part 9, p. 61. Jena, VEB Gustav Fischer Verlag. 